\title{
Development and comparison of enzyme- linked immunosorbent assays based on recombinant trimeric full-length and truncated spike proteins for detecting antibodies against porcine epidemic diarrhea virus
}

Chia-Yu Chang ${ }^{1,2}$, Ju-Yi Peng ${ }^{1}$, Yun-Han Cheng ${ }^{2}$, Yen-Chen Chang ${ }^{1,2}$, Yen-Tse Wư ${ }^{2}$ Pei-Shiue Tsai ${ }^{2}$, Hue-Ying Chiou ${ }^{3}$, Chian-Ren Jeng ${ }^{1,2}$ and Hui-Wen Chang ${ }^{1,2^{*}}$ (i)

\begin{abstract}
Background: Since 2010, outbreaks of genotype 2 (G2) porcine epidemic diarrhea virus (PEDV) have caused high mortality in neonatal piglets and have had devastating impacts on the swine industry in many countries. A reliable serological assay for evaluating the PEDV-specific humoral and mucosal immune response is important for disease survey, monitoring the efficacy of immunization, and designing strategies for the prevention and control of PED. Two PEDV spike (S) glycoprotein-based indirect enzyme-linked immunosorbent assays (ELISAs) were developed using G2b PEDV-Pintung 52 (PEDV-PT) trimeric full-length $S$ and truncated $S^{1-501}$ proteins derived from the human embryonic kidney (HEK)-293 cell expression system. The truncated $S^{1-501}$ protein was selected from a superior expressed stable cell line. The sensitivity and specificity of these two ELISAs were compared to immunostaining of G2b PEDV-PT infected cells and to a commercial nucleocapsid (N)-based indirect ELISA kit using a panel of PEDV negative and hyperimmune sera.

Results: The commercial N-based ELISA exhibited a sensitivity of 37\%, a specificity of 100\%, and a fair agreement (kappa $=0.37$ ) with the immunostaining result. In comparison, the full-length S-based ELISA showed a sensitivity of $97.8 \%$, a specificity of $94 \%$, and an almost perfect agreement ( $k a p p a=0.90)$ with the immunostaining result. Interestingly, the $\mathrm{S}^{1-501}$-based ELISA had even higher sensitivity of $98.9 \%$ and specificity of $99.1 \%$, and an almost perfect agreement $(\mathrm{kappa}=0.97)$ with the immunostaining result. A fair agreement $(\mathrm{kappa}<0.4)$ was seen between the commercial N-based ELISA and either of our S-based ELISAs. However, the results of the full-length S-based ELISA shared an almost perfect agreement $(k a p p a=0.92)$ with that of $S^{1-501}$-based ELISA.

\footnotetext{
* Correspondence: huiwenchang@ntu.edu.tw

${ }^{1}$ Graduate Institute of Molecular and Comparative Pathobiology, School of Veterinary Medicine, National Taiwan University, No. 1, Section 4, Roosevelt Rd., Taipei 10617, Taiwan

${ }^{2}$ School of Veterinary Medicine, National Taiwan University, Taipei 10617,

Taiwan

Full list of author information is available at the end of the article
}

(c) The Author(s). 2019 Open Access This article is distributed under the terms of the Creative Commons Attribution 4.0 International License (http://creativecommons.org/licenses/by/4.0/), which permits unrestricted use, distribution, and reproduction in any medium, provided you give appropriate credit to the original author(s) and the source, provide a link to the Creative Commons license, and indicate if changes were made. The Creative Commons Public Domain Dedication waiver (http://creativecommons.org/publicdomain/zero/1.0/) applies to the data made available in this article, unless otherwise stated. 
(Continued from previous page)

Conclusions: Both full-length S-based and $S^{1-501}$-based ELISAs exhibit high sensitivity and high specificity for detecting antibodies against PEDVs. Considering the high protein yield and cost-effectiveness, the $S^{1-501}$-based ELISA could be used as a reliable, sensitive, specific, and economic serological test for PEDV.

Keywords: Porcine epidemic diarrhea (PED), Serology, Indirect ELISA, Spike protein specific ELISA, Human embryonic kidney (HEK)-293 mammalian cell expression system

\section{Background}

Porcine epidemic diarrhea (PED) is a highly contagious disease that causes watery diarrhea, vomiting, electrolyte imbalance, and dehydration in piglets [1]. The morbidity and mortality rates are highly correlated with the age and the immune status of susceptible piglets [2]. The causative agent of PED is a single stranded, enveloped RNA virus named porcine epidemic diarrhea virus (PEDV), which belongs to the genera Alphacoronavirus, the family Coronaviridae, and the order Nidovirales [3]. The PEDV has an approximately 28-kilobase pair genome, including seven open reading frames, and encodes both non-structural and structural proteins [4]. The four major structural proteins are envelope $(\mathrm{E})$, membrane $(\mathrm{M})$, spike $(\mathrm{S})$, and nucleocapsid $(\mathrm{N})[1,2]$. The $\mathrm{N}$ protein produced during the early infection stages is the most abundant protein throughout the entire viral propagation process $[5,6]$. The $M$ protein is anchored on the envelope of the virion, which is formed by a small amount of $\mathrm{E}$ protein [7], whereas the $S$ protein protrudes in homologous trimer and shapes crown-like projections on the viral surface [8]. Among these structural proteins, the $\mathrm{S}$ protein, a superficial glycoprotein, is responsible for establishing infection and inducing neutralizing antibodies $[9,10]$. The $\mathrm{S}$ protein can be divided into the S1 region (amino acid [aa] 1-789) and S2 region (aa 790-1383) [11]. Generally, the $\mathrm{S} 1$ region, which can be further subdivided into five structural domains $\left(\mathrm{S}^{0}, \mathrm{~S} 1^{\mathrm{A}}, \mathrm{S} 1^{\mathrm{B}}, \mathrm{S} 1^{\mathrm{C}}\right.$, and $\left.\mathrm{S} 1^{\mathrm{D}}\right)$, dominates the viral-host recognition and receptor binding, whereas the S2 region triggers viral fusion and internalization $[9,12]$. Additionally, three neutralizing epitopes on the spike protein of PEDV have been reported: including CO-26 K equivalent epitope (COE epitope; aa 499-638) [13], S1D epitope (aa 636-789) [14], and 2C10 epitope (aa 13681374) [15]. Recently, the $\mathrm{S}^{\mathrm{O}}, \mathrm{S}^{\mathrm{A}}$, and $\mathrm{S} 1^{\mathrm{B}}$ domains, as well as the C-terminus of S2, were demonstrated to participate in virus neutralization $[8,16,17]$. The functions and the importance of the $S$ protein of PEDV make it a key target for vaccine development and immune status evaluation.

PED was first reported in Europe and Asia in the early 1970 s and over the following thirty years, reports emerged from several more countries [18]. Recently, genotype 2 (G2) PEDV, which has a high virulence, was found to affect Asia and America, resulting in significant economic losses in the swine industries, especially in China, Korea, Japan, Taiwan, US, Canada, and Mexico [1, 3]. The mortality rate in seronegative neonatal piglets after high virulent PED infections reached 90-95\% [19-21]. Currently, the disease is still circulating in several countries, therefore, evaluating the PEDV-specific immune response of piglets and sows is essential. This evaluation will allow us to determine the efficacy of immunization and to predict the trend of immune status in the field to create strategies for the prevention and control of PED.

Currently, several enzyme-linked immunosorbent assays (ELISAs) have been established and commercialized to detect systemic IgG or mucosal IgA against PEDV [22-27]. Commercially available ELISA kits for PEDV are mainly based on the $\mathrm{N}$ protein of PEDV, because $\mathrm{N}$ protein is the dominant protein. It is massively produced during the infection procedure and is able to provoke strong immune responses [24]. However, previous studies have revealed that whole virus, $N$ protein, or $M$ protein-based ELISA may detect cross-reactive antibodies against other swine coronaviruses [25]. On the other hand, several PEDV S-based ELISAs have been developed [26-28] and confirmed no cross-reactivity with other porcine coronaviruses [26, 28]. These results suggest that S-based ELISA may be more suitable for detecting PEDV-specific antibodies.

Mammalian expression systems have the unique ability to produce proteins with complex conformational structures containing the appropriate post-translational modifications $[29,30]$. The precise folding and appropriate modifications of the target antigens are key for both vaccine and serological assay development. To date, only one G2b S1 (aa 1-781)based ELISA has been developed from a mammalian protein expression system [26]. We earlier applied human embryonic kidney (HEK) 293 cell derived PEDV-Pintung 52 (PT) trimeric full-length $\mathrm{S}$ protein-based ELISA for the detection of antibodies against homologous strains [31, 32]. However, the differences in performance between the trimeric full-length S-based PEDV ELISA, that contains all epitopes spanning the complete viral $\mathrm{S}$ protein, and the truncated S-based PEDV ELISA, that contains partial epitopes of the $S$ protein, in the detection of antibodies against heterologous and historic PEDV strains is unknown.

In addition to sensitivity and specificity, cost effectiveness is also an important concern in the development of ELISA 
kits. In the present study, we first determined the expression level of a panel of different truncated S proteins generated in our previous study [17]. A truncated $S$ protein that comprised the residues of aa $1-501$ of the $S$ protein $\left(S^{1-501}\right)$ was selected as it showed the highest protein yield. The sensitivity, specificity, and interrater agreements of G2b PEDV trimeric full-length $S$ and $S^{1-501}$ protein indirect ELISAs were compared with those of a commercial N-based indirect ELISA kit using a panel of PEDV hyperimmune serums targeting homologous or heterologous strains of PEDVs.

\section{Results}

\section{Comparison of the protein yield of different truncated PEDV S proteins}

In order to select the truncated $S$ protein with the highest expression levels in HEK 293 cells from which to develop a cost-effective ELISA kit, the yield of different truncated PEDV $S$ proteins was compared. The total amount of full-length $S$ protein purified from $40 \mathrm{~mL}$ of culture supernatant was $80 \mu \mathrm{g}$, compared to the total amount of purified $\mathrm{S}^{1-435}, \mathrm{~S}^{1-485}, \mathrm{~S}^{1-501}, \mathrm{~S}^{1-509}, \mathrm{~S}^{1-575}$, and $S^{1-639}$ proteins, which was $113 \mu \mathrm{g}, 1071 \mu \mathrm{g}, 1600 \mu \mathrm{g}$, $486 \mu \mathrm{g}, 45 \mu \mathrm{g}$, and $422 \mu \mathrm{g}$, respectively. Along with the high-purity full-length $S$ protein [32], the $S^{1-501}$ protein was also chosen as a candidate for the development of ELISA due to its superior protein expression level compared to other truncated S proteins in HEK-293 cells. The purity and quality of the $S^{1-501}$ protein were confirmed by sodium dodecyl sulfate (SDS)-polyacrylamide gel electrophoresis (PAGE) (Additional file 1: Figure S1).

\section{Immunostaining of serum and colostrum samples against G2b PEDV-PT infected Vero cells}

A panel of 213 PEDV negative serum samples and was selected from well-managed, no PEDV exposure history, conventional and SPF farms. A panel of 90 positive serum samples was selected from conventional SPF pigs with
PEDV infection history either by experimental G2b PEDV-PT inoculation or by oral feedback using the intestinal homogenate derived from G2b PEDV-infected piglets. The anti-PEDV titers of these serum samples were characterized by either immunofluorescence assay (IFA) or immunocytochemical staining (ICC). The representative immunostained images were shown in Fig. 1. While all samples exhibited high staining backgrounds at the dilutions $<1: 160$ in the immunostainings, the titer of the serum samples above 1:160 dilution was determined by two-fold serial dilution in our study. The immunostaining titers of all the negative samples, including $\mathrm{C}-\mathrm{N}$ pigs and SPF-N pigs, were $<1: 160$, thus confirming them as negative serum samples. The immunostaining titers of the positive group C-I pigs ranged from 1:320-1:5120, including 7 serum samples of 1:320; 8 serum sample of 1:640, 9 serum samples of 1:1280, 15 serum samples of 1:2560, and 11 serum samples of 1:5120. The immunostaining titers of all fifteen SPF-I pigs were consistently 1:5120. The serum titers of the pigs varied from 1:1280- $\geq 1: 20480$, including 1 serum sample of 1:1280, 5 serum samples of $1: 2560,4$ serum samples of 1:5120, 11 serum samples of 1:10240, and 5 serum samples of $\geq 1: 20480$. All serum samples from the positive group were confirmed positive by the immunostaining. All colostrum (5/5) of the SPF sows had the titer $<1: 160$, representing no detectable PEDV-specific IgA. However, all colostrum samples of the conventional sows were positive, including 9 colostrum of 1:160, 6 colostrum of 1:320, 3 colostrum of 1:640, 2 colostrum of 1 : 1280 , and 3 colostrum of 1:2560.

\section{Determination of assay specificity of commercialized $\mathrm{N}$ protein-based ELISA}

According the manufacturer's guidelines, the cut-off value of $\mathrm{N}$ protein-based ID Screen ${ }^{\circ}$ PEDV Indirect (IDVet) is 0.6 , so the sample to positive ratio ( $\mathrm{S} / \mathrm{P}$ ratio) of the serum sample must be $>0.6$ to be considered positive. As shown
A.

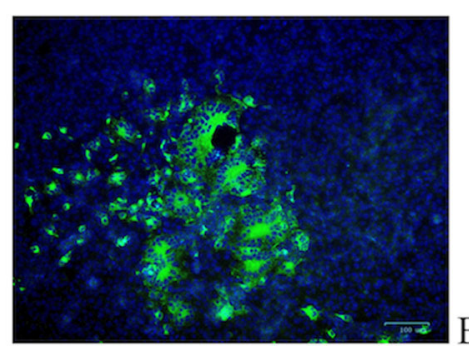

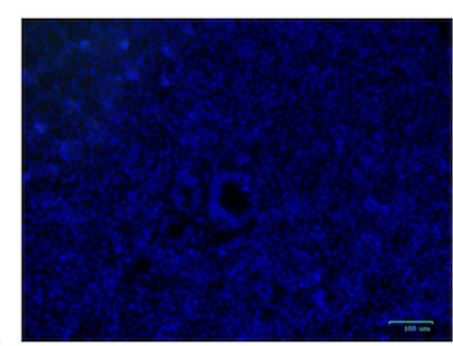

B.

Fig. 1 Representative images of immunostaining of serum samples against G2b PEDV-PT infected Vero cells. Vero cells were seeded onto 96-well plates and grown overnight until reaching $90 \%$ confluency. The Vero cells were challenged with $1000 \mathrm{TCI} \mathrm{D}_{50} / \mathrm{mL}$ of G2b PEDV-PT-P6 diluted in post-inoculation (PI) medium. Vero cells with syncytial cells, the cytopathic effect (CPE) of PEDV, were fixed with acetone after $24 \mathrm{~h}$ of incubation. Each serum sample from different sources was serially diluted from 160-fold to 20,480-fold, then added to the plates and incubated for $1 \mathrm{~h}$. Antipig IgG antibodies conjugated with horseradish peroxidase (HRP) or fluorescence were used to probe serum IgG on the syncytial cells. A positive signal was found in the Vero cells showing CPE. a The representative "positive" result of immunostaining using the serum sample from the C-I group at a 640-fold dilution. b The representative "negative" result of immunostaining using the serum sample from the C-N group at a 640-fold dilution. The bars represent the scale of $100 \mu \mathrm{m}$ 
in Table 1, 55 serum samples randomly picked from the $\mathrm{C}-\mathrm{N}$ pigs, as well as 14 serum samples from the SPF-N pigs, were found to be negative by screening with the $\mathrm{N}$ protein-based ID Screen ${ }^{\circledR}$ PEDV Indirect (IDVet). Twentythree serum samples were randomly chosen from C-I pigs, eight out of twenty-three $(8 / 23)$ were determined to be positive, and 15 serum samples were negative. Eleven of fourteen (11/14) serum samples from SPF-I pigs were positive, and only three were negative. On the other hand, four out of twenty-six $(4 / 26)$ serum samples from Sow-F pigs were positive, and the remaining twenty-two serum $(22 / 26)$ samples were negative. Using the results of the immunostainings as the gold standard, the sensitivity and specificity of the $\mathrm{N}$ protein-based ID Screen ${ }^{\circ}$ PEDV Indirect (IDVet) were 37 and $100 \%$, respectively. The kappa value between ICC staining and the $\mathrm{N}$ protein-based ID Screen ${ }^{\circ}$ PEDV Indirect (IDVet) was 0.37, which represents a "fair agreement". The distribution between the results of the $\mathrm{N}$ protein-based ELISA and the immunostaining titers is presented in Fig. 2.

\section{Determination of the cut-off value, sensitivity, and specificity of full-length S-based ELISA}

Using the receiver operating characteristic (ROC) analysis as shown in Fig. 4a, the cut-off value of full-length S-based ELISA was determined to be 0.432 to obtain the $97.8 \%$ sensitivity and $94 \%$ specificity. As summarized in Table 1 , starting with a cut-off value of 0.432 , forty-eight out of fifty $(48 / 50)$ serum samples from C-I pigs, fourteen (14/ 14) serum samples from SPF-I pigs, and twenty-six (26/ 26) serum samples from Sow-F pigs were found to be positive. Only two out of fifty $(2 / 50)$ serum samples from $\mathrm{C}-\mathrm{I}$ pigs had false negative results. Eleven of one hundred ninety-nine (11/199) serum samples from the C-N group had false positive results, while the remaining serum samples (188/199) in the C-N group and all (14/14) serum samples in the SPF-N group were negative. With the kappa value of 0.90 , the interrater agreement of the fulllength S-based ELISA and the immunostainings is almost perfect. The distribution between the immunostaining titers and the results of full-length S-based ELISA, the distribution is shown in Fig. 3b.

\section{Determination of cut-off value, sensitivity, and specificity of $S^{1-501}$-based ELISA}

Using the ROC analysis, the cut-off value of $\mathrm{S}^{1-501}$-based ELISA was determined to be 0.547 to obtain the $98.9 \%$ sensitivity and $99.1 \%$ specificity (Fig. 5a). As shown in Table 1 and Fig. 4, except for one serum from the C-I pigs, all C-I (49/50), SPF-I (14/14), and Sow-F (26/26) samples were positive with a cut-off value of 0.547 . Except two serum samples (2/199) in the C-N group that were positive, the other serum samples (197/199) in the C-N group and all serum samples in the SPF-N (14/14) group were negative. The kappa value of $S^{1-501}$-based ELISA with a cut-off value of 0.547 was 0.97 , meaning the results of $\mathrm{S}^{1-}$ ${ }^{501}$-based ELISA had an almost perfect agreement with that in the immunostaining results (Fig. 4b).

\section{Agreement comparisons between serological assays}

Figure $5 \mathrm{a}$ and $\mathrm{b}$ showed the distribution of the results between assays. The kappa values between the commercialized N protein-based ELISA and the full-length S-based ELISA and $S^{1-501}$-based ELISA were 0.33 and 0.38 , respectively, meaning the assays show fair agreements. In contrast, the agreement between the full-length S-based ELISA and the $\mathrm{S}^{1-501}$-based ELISA was almost perfect with a kappa value of 0.92 .

Table 1 The summary of the result of serological assays in each group. (+): positive; (-): negative; NE: non-examination; C-N: conventional PEDV naïve pigs; C-I: experimental PEDV inoculated conventional pigs; SPF-N: specific pathogen free PEDV naïve pigs; SPF-I: experimental PEDV inoculated SPF pigs; Sow-F: PEDV-feedback sows. NE: non-examined

\begin{tabular}{|c|c|c|c|c|c|c|c|}
\hline \multirow[t]{2}{*}{ Group } & \multirow{2}{*}{$\begin{array}{l}\text { No. } \\
\text { of } \\
\text { pigs }\end{array}$} & \multicolumn{2}{|c|}{ Commercial N-based ELISA } & \multicolumn{2}{|c|}{ Full-length S-based ELISA } & \multicolumn{2}{|c|}{$\mathrm{S}^{1-501}$-based ELISA } \\
\hline & & + & - & + & - & + & - \\
\hline \multirow[t]{2}{*}{ C-N } & 55 & 0 & 55 & 5 & 50 & 0 & 55 \\
\hline & 144 & $\mathrm{NE}$ & $\mathrm{NE}$ & 6 & 138 & 2 & 142 \\
\hline \multirow[t]{2}{*}{$C-1$} & 23 & 8 & 15 & 23 & 0 & 23 & 0 \\
\hline & 27 & $\mathrm{NE}$ & NE & 25 & 2 & 26 & 1 \\
\hline SPF-N & 14 & 0 & 14 & 0 & 14 & 0 & 14 \\
\hline SPF-I & 14 & 11 & 3 & 14 & 0 & 14 & 0 \\
\hline Sow-F & 26 & 4 & 22 & 26 & 0 & 26 & 0 \\
\hline \multicolumn{2}{|c|}{ Sensitivity } & \multicolumn{2}{|l|}{$37 \%$} & \multicolumn{2}{|c|}{$97.8 \%$} & \multicolumn{2}{|c|}{$98.9 \%$} \\
\hline \multicolumn{2}{|c|}{ Specificity } & \multicolumn{2}{|l|}{$100 \%$} & \multicolumn{2}{|c|}{$94 \%$} & \multicolumn{2}{|c|}{$99.1 \%$} \\
\hline \multicolumn{2}{|c|}{ Kappa value } & \multicolumn{2}{|l|}{0.37} & \multicolumn{2}{|c|}{0.90} & \multicolumn{2}{|c|}{0.97} \\
\hline
\end{tabular}




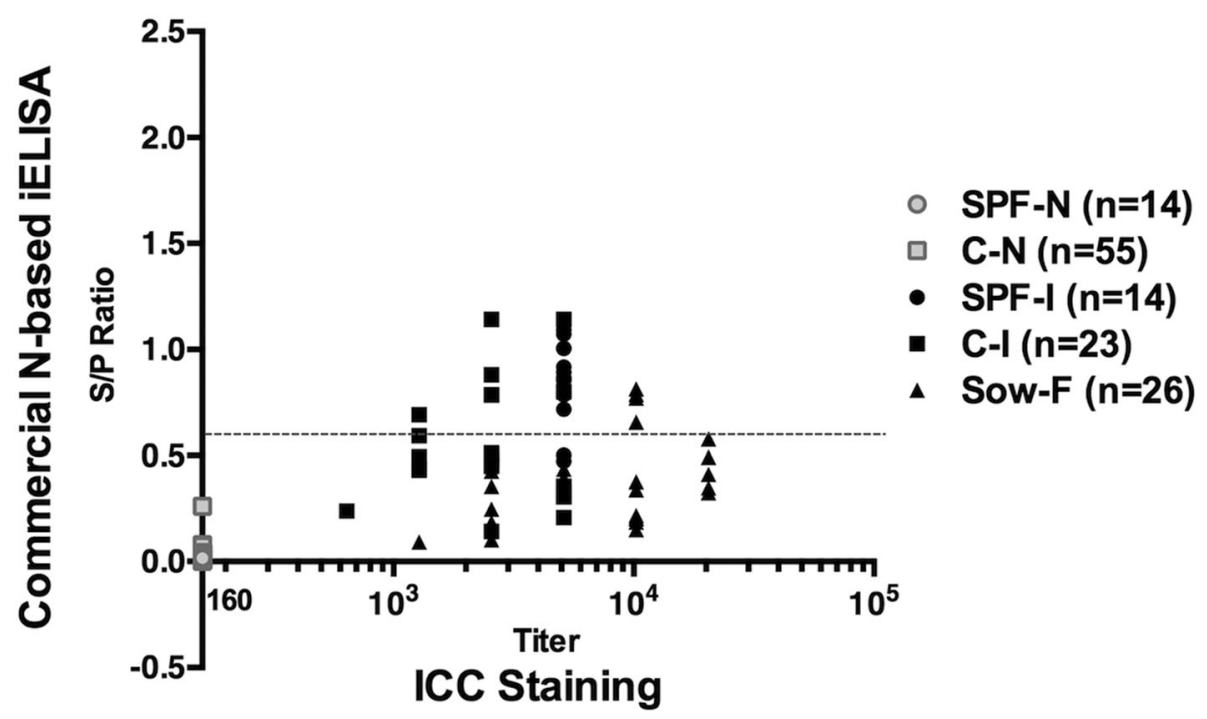

Fig. 2 Distribution of the results of the immunostaining and commercial N-based ELISA. The immunostaining titers of each serum sample were presented as logarithms with the base 10. Serum samples which were negative for the immunostaining are denoted by 0 . The results of the commercial N-based ELISA kit were presented by the sample to positive ratio (S/P ratio). S/P ratio $=[($ sample OD - mean OD of negative controls) / (mean OD of positive controls - mean OD of negative controls)]. The dotted line represents the threshold of an S/P ratio of 0.6 of the commercial N-based ELISA, as per the manufacturer's instructions. C-N (with grey square icon): conventional PEDV naïve pigs; C-I (with black square icon): experimental PEDV inoculated conventional pigs; SPF-N (with grey round icon): specific pathogen free PEDV naïve pigs; SPF-I (with black round icon): experimental PEDV inoculated SPF pigs; Sow-F (with black triangle icon): PEDV-feedback sows

\section{Colostrum IgA detection using full-length S-based and $S^{1-501}$-based ELISAs}

To determine the performance of our S-based ELISAs in detection of colostrum PEDV specific IgA, twenty-three colostrum samples were collected from PEDV seropositive conventional sows with PED outbreak and feedback history in 2 months as positive control and five colostrum samples were collected from PEDV seronegative SPF sows as negative control. The PEDV specific IgA titers were determined by using the ICC assay and ranged from 1:160-1:2560 and $<1: 160$ in positive and negative colostrum samples, respectively. As shown

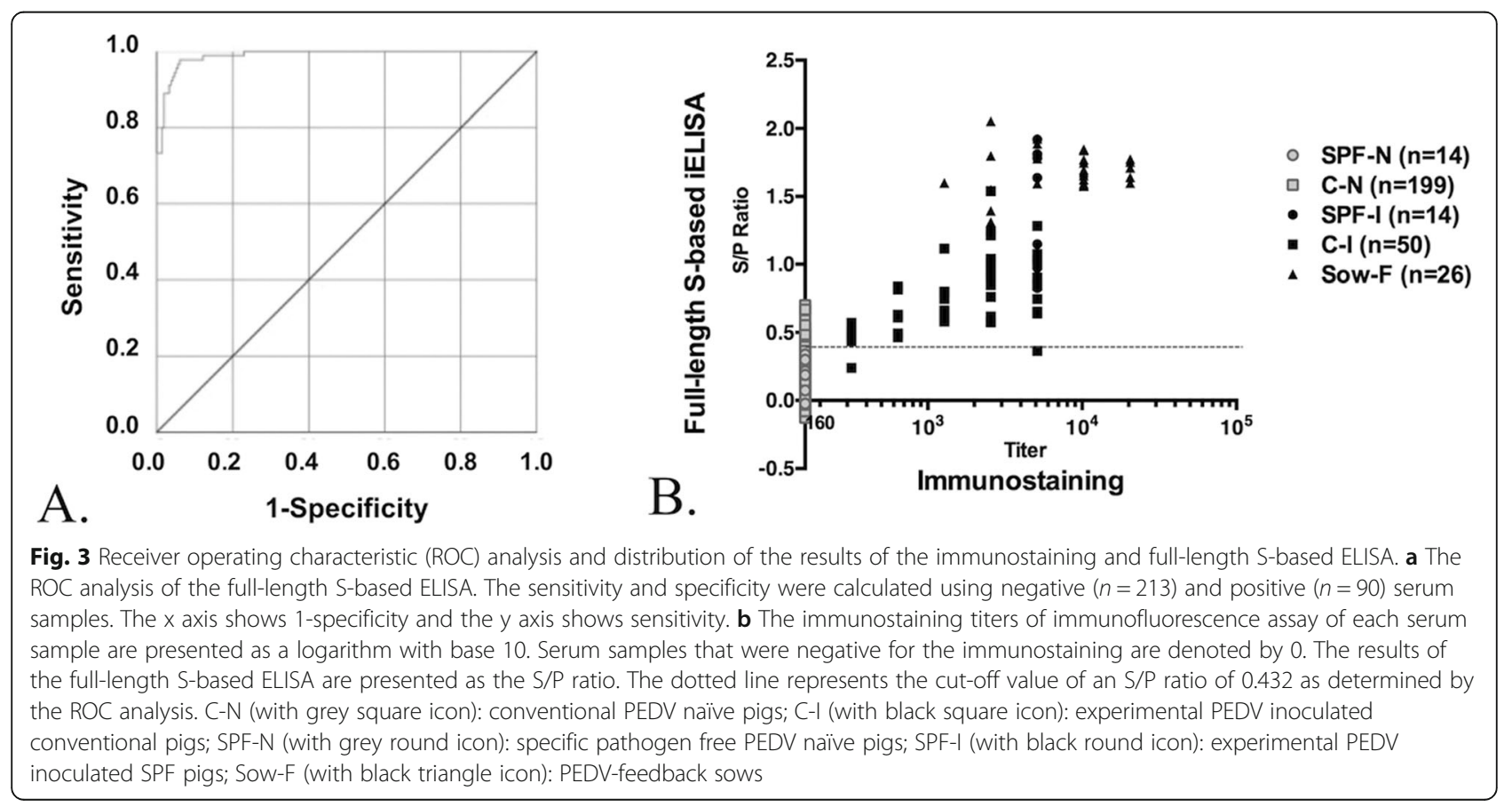




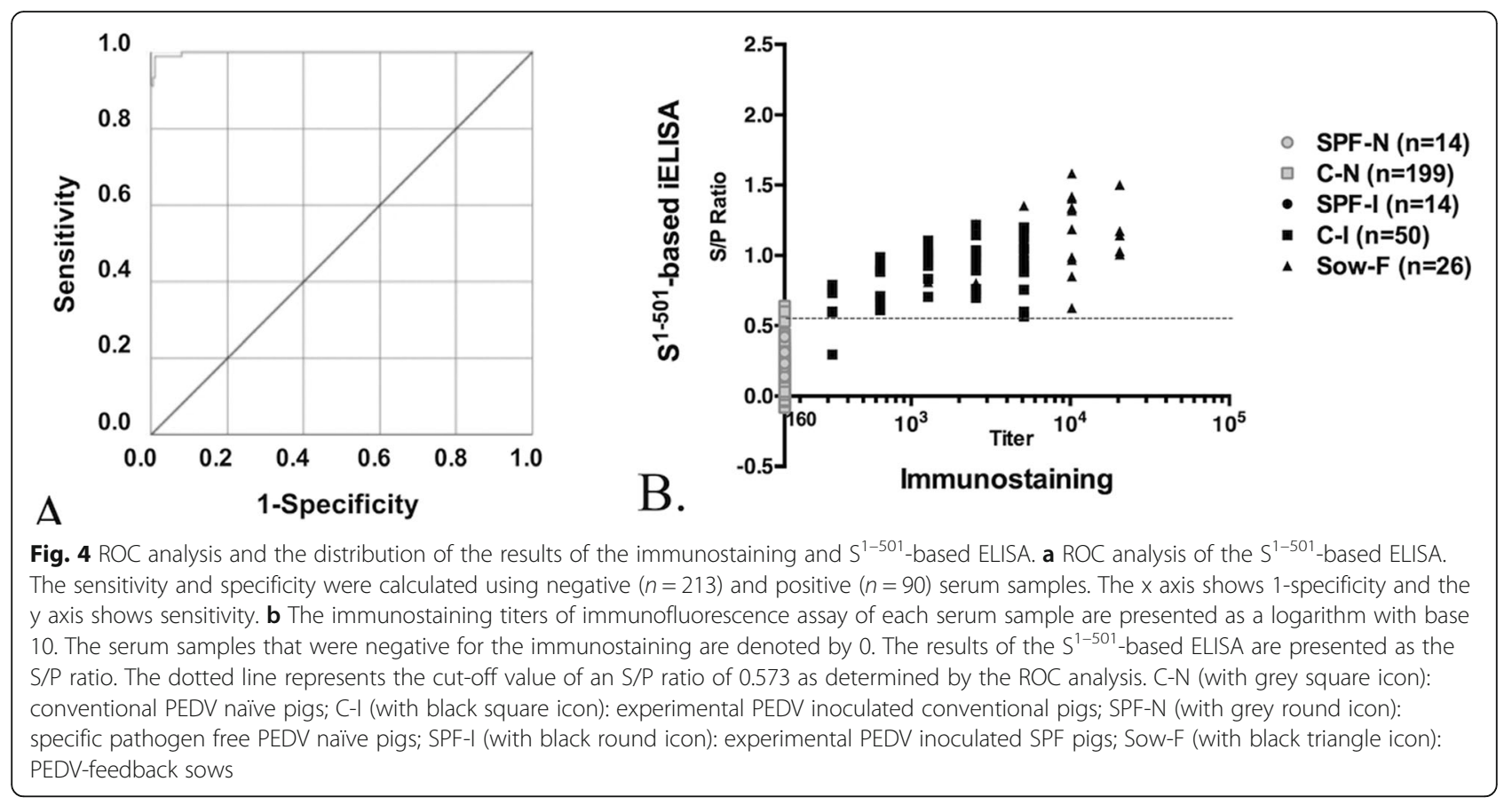

A.

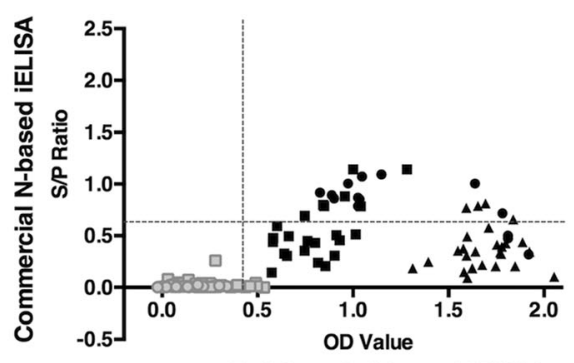

Full-length S-based iELISA
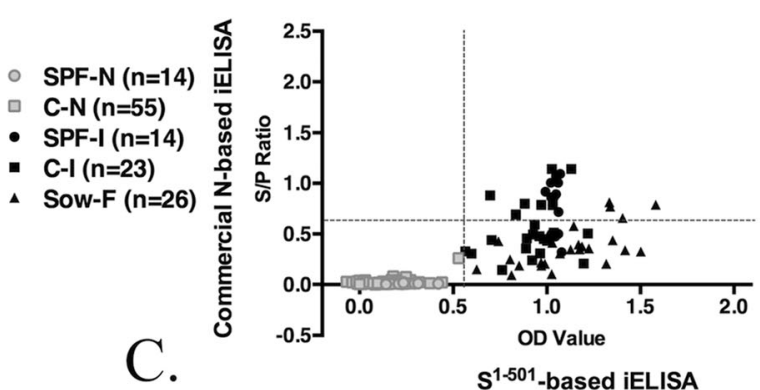

- SPF-N ( $n=14)$

- $C-N(n=55)$

- SPF-I $(n=14)$

- $C-I(n=23)$

- Sow-F ( $n=26)$

B.

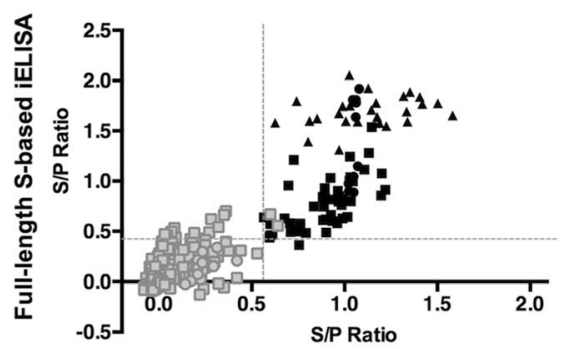

- SPF-N ( $n=14)$

- $C-N(n=199)$

- SPF-I $(n=14)$

- C-I $(n=50)$

- Sow-F $(n=26)$

Fig. 5 Comparison between commercial N-based, full-length S-based, and $\mathrm{S}^{1-501}$-based ELISAs. a The distribution of the results of the full-length S-based and commercial N-based ELISAs. The vertical dotted line represents the cut-off value of the full-length-based ELISA. The horizontal dotted line represents the threshold of the commercial N-based ELISAs, as suggested by the manufacturer. $\mathbf{b}$ Distribution of the results of $\mathrm{S}^{1-501}$-based and full-length S-based ELISAs. The vertical dotted line represents the cut-off value of the $S^{1-501}$-based ELISA. The horizontal line represents the cut-off value of the S/P ratio of the full-length-based ELISA. c The distribution of the results of $\mathrm{S}^{1-501}$-based and commercial N-based ELISAs. The vertical dotted line represents the cut-off value of the $S^{1-501}$-based ELISA. The horizontal dotted line represents the threshold of the commercial $\mathrm{N}$-based ELISAs, as suggested by the manufacturer. C-N (with grey square icon): conventional PEDV naïve pigs; C-I (with black square icon): experimental PEDV inoculated conventional pigs; SPF-N (with grey round icon): specific pathogen free PEDV naïve pigs; SPF-I (with black round icon): experimental PEDV inoculated SPF pigs; Sow-F (with black triangle icon): PEDV-feedback sows 


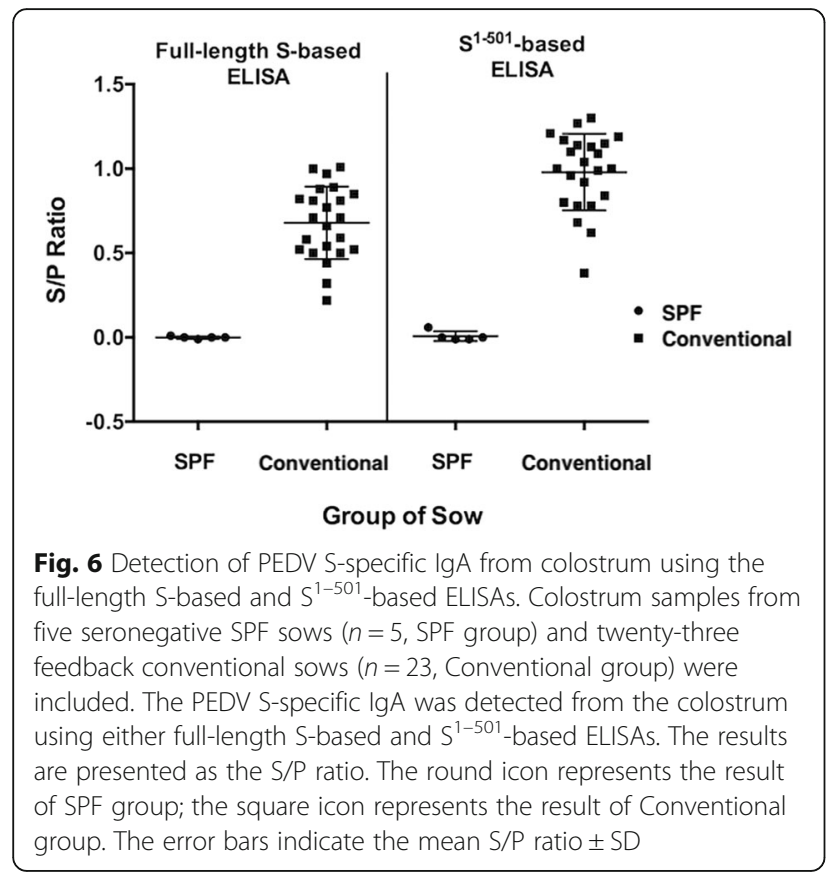

in Fig. 6, the S/P ratio of the colostrum IgA from the PEDV sero-negative SPF sows was approximately $0 \pm$ 0.01 in the full-length $\mathrm{S}$-based or $\mathrm{S}^{1-501}$-based ELISA. Importantly, the $\mathrm{S} / \mathrm{P}$ ratio of the colostrum IgA from the feedback conventional sows, which ranged from 0.221.00 and $0.38-1.27$ in the full-length S-based and $\mathrm{S}^{1-501}$. based ELISA, respectively, was higher than the $\mathrm{S} / \mathrm{P}$ ratio from PEDV sero-negative SPF sows.

\section{Characterization and production of S protein of G1b PEDV}

We confirmed that both full-length $S$ and $S^{1-501}$-based ELISAs could be used to detect antibodies against homologous or G2b PEDVs. To evaluate whether full-length $S$ and $S^{1-501}$-based ELISAs were able to detect antibodies targeting for heterologous historic PEDVs, the full-length sequence of the $\mathrm{S}$ gene of a Taiwan historic G1b PEDV-HC070225 strain was synthesized and the codon optimized for HEK-293 cells. The S protein of the G1b PEDV-HC070225 strain was successfully expressed and characterized via immunocytochemical (ICC) staining with anti-V5 tag antibody (Fig. 7a, b). After protein purification, the molecular weight of the G1bb PEDV $S$ protein was identified at approximately $250 \mathrm{kDa}$ by western blotting (Fig. 7c).

\section{Evaluation of cross reactivity of serological assays using G1b PEDV S-hyperimmune serum}

Following three rounds of immunization, the immunostaining titer of the serum derived from G1b PEDVHC070225 S protein-immunized pigs was determined to be 1:5120. The S/P ratios of the serum against full-length S-based ELISA and the $\mathrm{S}^{1-501}$-based ELISA were 1.58 and 1.17, respectively. Since the cut-off values of S-based
A.

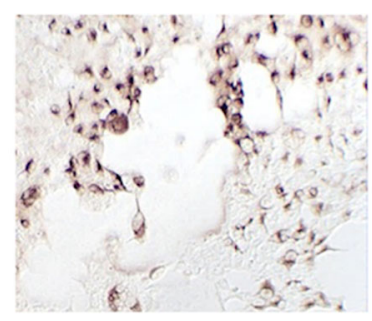

B.

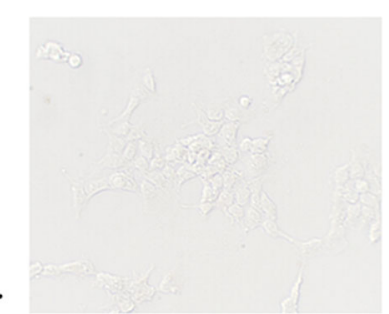

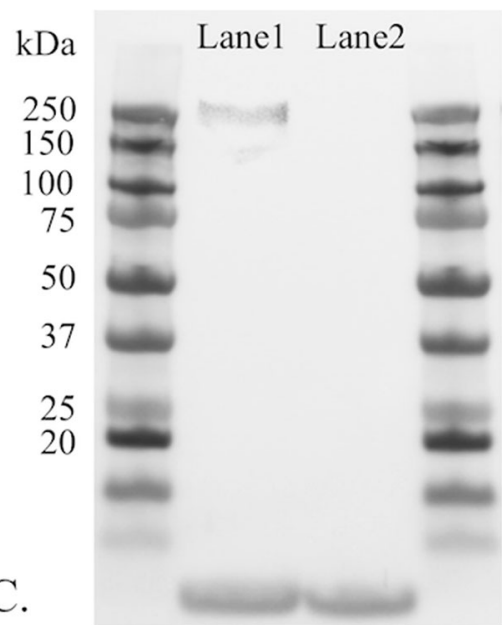

Fig. 7 Expression and characterization of G1b PEDV S protein by ICC staining and western blotting. a ICC staining of G1b PEDV S-expressing HEK cells using anti-V5 tag antibody. The cells were fixed on the plates using acetone, probed using 1000-fold diluted anti-V5 tag antibody, and detected using anti-mouse IgG antibody conjugated with HRP. The coloration procedure was carried out using the DAB system. $\mathbf{b}$ The negative control of the ICC staining of non-transfected HEK cells. The cells were probed with anti-V5 tag antibody following by the anti-mouse IgG antibody conjugated with HRP to distinguish the non-specific signals. c The molecular weight of the purified G1b PEDV S protein (Lane 1) was estimated by western blotting. The purified G1b PEDV S protein was denatured in NuPAGE ${ }^{\circledR}$ LDS sample buffer containing the NuPAGE ${ }^{\circledR}$ reducing agent and boiled at $95^{\circ} \mathrm{C}$ for 5 min, then, separated by SDS-PAGE, transferred onto the PVDF membrane, and stained with anti-V5 tag antibody. The HEK cell lysate was used as the negative control (Lane 2). The ladder is shown in kilodalton (kDa) 
ELISA and $\mathrm{S}^{1-501}$-based ELISA were 0.432 and 0.573 , respectively, the results were interpreted as positive.

\section{Discussion}

Two PEDV S protein-based ELISAs, the full-length Sbased and the truncated $S^{1-501}$-based ELISAs, were developed in this study. The standard that was used for comparison in this study is immunostaining against G2b PEDV-PT infected Vero cells. Based on this, our results show that the performance of the $S^{1-501}$-based ELISA in detection of PEDV specific IgG is better than that of the full-length S-based ELISA and the commercialized PEDV N-based ELISA. Furthermore, we also demonstrated that both PEDV S protein-based ELISAs are able to detect the IgA antibodies in colostrum and both G1b and G2 PEDV specific serum IgG. Because of its excellent performance and high protein yield, the $S^{1-501}$ based ELISA is the most affordable and efficient choice for developing serological assays for PEDV.

Several ELISAs for detecting PEDV-specific antibodies have been established in previous studies in which the majority of the coating antigens, including $\mathrm{S} 1, \mathrm{~N}$, or $\mathrm{M}$ protein $[23,24,28,33]$, were expressed by a prokaryotic protein expression system to achieve a high yield of protein production. However, protein expressed using a prokaryotic expression system may lack the appropriate protein folding and the complexity of post-translational modifications, such as glycosylation, which could lead to a reduction in the sensitivity and specificity of ELISA kits. In this study, a HEK-293 mammalian expression system was used to express the coating antigens, S proteins, for the development of PEDV ELISAs. The $\mathrm{S}$ protein of PEDV is a key target for virus neutralization and vaccine development $[1,4]$ and contains several neutralizing epitopes [8, 13, 15-17], which may be an important indicator for evaluating immunity against PEDV [1]. The $S$ protein of coronavirus has been demonstrated to display a complex structure and contains at least 21-35 predicted $\mathrm{N}$-glycosylation sites. The mammalian protein expression system allows for proper formation of complex multidimensional structures and post-translational modifications, thereby generating antigens that can attain a high sensitivity in ELISAs [12, 34, 35]. The S protein of PEDV is a trimeric protein [36] and, similar to other coronaviruses, the trimeric form of the $\mathrm{S}$ protein may contain more conformational epitopes than a monomeric protein [37]. Therefore, the full length of the trimeric spike protein containing all S1 and S2 epitopes is considered an important target for the development of ELISAs [8, 13-16]. However, the large molecular size of the full-length $S$ protein presents a challenge for large scale protein expression and production [32]. With these difficulties, many studies have preferred to use S1 instead of full-length $\mathrm{S}$ to conduct both vaccine and serological assay development $[28,31,38]$. The high sensitivity and specificity of the ELISA developed using the S1 protein of PEDV produced by Freestyle 293-F cells [26] suggests that truncated $S$ proteins might also be good candidates for developing PEDV S-based ELISA. However, the performance of the S1-based ELISA has never been compared with the full-length PEDV S-based ELISA. Based on the comparison of the protein yields of different truncated S protein-expressing stable HEK-293 cells, the $\mathrm{S}^{1-501}$-based ELISA was successfully developed. Interestingly, the full-length S-based ELISA was not superior in terms of its ability to detect PEDV-specific antibodies compared with the truncated $S^{1-501}$-based ELISAs. In the present study, the $S^{1-501}$ protein was prepared from the supernatant of a stable cell line to reduce the expenses for transfection and expression. Furthermore, the $S^{1-501}$ expressing stable cell line was selected based on its superior protein expression quantity $(40 \mu \mathrm{g} /$ $\mathrm{mL}$ culture supernatant) to others. For ELISA application, approximately $20 \mu \mathrm{g}$ of $\mathrm{S}$ protein was used for preparing a 96-well plate ELISA. These suggest that each $\mathrm{mL}$ of culture supernatant could be used to prepare two ELISA plates. The excellent performance of the truncated $S^{1-501}$-based ELISA with the highest protein expression level indicates this would be a good antigen and for PEDV ELISA. Our findings are similar to those of previous reports in which $S$ protein was found to be an ideal antigen for developing ELISA, with a higher sensitivity and better specificity than $\mathrm{N}$ protein-based ELISAs $[27,39]$. Both full-length S-based and $\mathrm{S}^{1-501}$-based ELISAs have much better sensitivities than the commercial $\mathrm{N}$-based ELISA kit. The S-based ELISAs used in this study can be used in both SPF pigs, conventional pigs, and sows, whereas commercial N-based ELISAs only perform well in SPF pigs, which have a relatively low background and stronger immune response. The Sbased ELISAs can be used to detect the immune response and the immune status of the population and is an indispensable tool in evaluating the efficacy of PEDV vaccines [39].

Currently, several G1b and G2b PEDV strains are circulating in North America and Asia [40-42]. Therefore, establishing a serological assay that is able to detect antiG1 and G2b PEDV antibodies is important in order to evaluate the immune status of swine populations. Since there is no clinically confirmed serum against G1b PEDV available in our lab, the full-length of the G1b PEDV $S$ protein derived from a historic Taiwan strain was generated and used as an antigen to immunize pigs for the generation of hyperimmune serum against $\mathrm{S}$ protein from G1b PEDV strains. The $S$ protein, in particular $\mathrm{S} 1$, has been demonstrated to have a relatively high heterogeneity between genotypes and clusters (the identity of amino acid ranges from 91 to $99.6 \%$ ) compared with 
other proteins [43]. The amino acid sequence of fulllength $S$ and $S^{1-501}$ of the G2b PEDV-PT strain share approximately $94 \%$ and $86-88 \%$ identity with G1b PEDV $\mathrm{S}$ proteins, respectively. We demonstrated that the $\mathrm{S}^{1-}$ 501 ELISAs derived from the G2b PEDV-PT strain, showed a comparable performance with the full-length S-based ELISA in detecting homologous G2b and heterologous G1b PEDV-specific antibodies.

\section{Conclusion}

In this study, both full-length S-based and $\mathrm{S}^{1-501}$-based ELISAs performed well in tests with serum samples from different sources as well as with colostrum samples from sow. Moreover, the two ELISAs were suitable for use in the detection of both anti-G1b and G2b PEDV antibodies. Taking into account its performance and cost, $\mathrm{S}^{1-501}$-based ELISA, with a sensitivity and specificity of close to $100 \%$ and a high protein yield, is the best choice for developing a PEDV ELISA.

\section{Methods}

\section{Ethics statement}

The procedures involving animals were approved and permitted by the Institutional Animal Care and Use Committee (IACUC) of National Taiwan University (NTU; Taiwan, Republic of China) and carried out under the regulations of the IACUC protocol at NTU with the approval number of 106-EL-00054.

\section{Specimen information}

A total of 303 serum samples were used in this study: 213 negative control samples from high managed, no PEDV exposure history farms (199 samples from the conventional farm and 14 samples from an SPF farm); and 90 positive control samples from pigs with PEDVG2b infection history (50 samples from G2b PEDV-PT challenged conventional post-weaning pigs, 14 samples from G2b PEDV-PT challenged SPF pigs, and 26 samples from sows received G2b PEDV strain feedback). Hence, the serum samples from pigs used in this study can be divided in to five groups: conventional PEDV naïve (C-N) pigs; experimental G2b PEDV-PT inoculated conventional (C-I) pigs; specific pathogen-free PEDV naïve (SPF-N) pigs; experimental G2b PEDV-PT inoculated SPF (SPF-I) pigs; and G2b PEDV-feedback sows (Sow-F) (Table 1). All PEDV-PT experimentally challenged animals orally received $5 \times 10^{5} \mathrm{TCID}_{50}$ of G2b PEDV-PT passage 6\&7. The serum samples from these animals were collected two weeks after the PEDV challenge. All post-weaning SPF pigs were purchased from the Animal Technology Institute of Taiwan (ATIT). For detection of PEDV specific colostrum IgA, twenty-three colostrum samples from PEDV seropositive conventional sows with PED outbreak and feedback history in the previous 2 months and 5 colostrum samples from PEDV sero-negative SPF sows were used.

\section{PEDV isolation and PEDV-infected Vero cell preparation} The G2b PEDV-PT strain (GenBank: KY929405) was prepared as previously described [44]. The 6th passage of PEDV-PT (PEDV-PT-P6) was used as the antigen for the immunostainings in the present study. In brief, to prepare the virus-infected Vero cell plates with visible cytopathic effect $(\mathrm{CPE})$, i.e. the presence of syncytial cells, the Vero cells were seeded onto 96-well culture plates (Thermo Fisher Scientific, Waltham, MA, USA) with a $90 \%$ confluence after $18 \mathrm{~h}$. The cells were washed with PBS (Gibco, Gaithersburg, MD, USA) three times and inoculated with $1000 \mathrm{TCID}_{50} / \mathrm{mL}$ of PEDV-PT-P6 diluted in post-inoculation (PI) medium, containing DMEM (Gibco), 0.3\% tryptose phosphate broth (Sigma, St. Louis, MO, USA), 0.02\% yeast extract (Acumedia, Lansing, CA, USA), and $10 \mu \mathrm{g} / \mathrm{mL}$ of trypsin (Gibco). After $24 \mathrm{~h}$ of incubation, the CPE was observed, the supernatant was discarded and the PEDV-infected Vero cells with $10 \%$ area covered by cytopathic effect (CPE) were fixed with $80 \%$ acetone (Sigma) for $20 \mathrm{~min}$. After removing the acetone and air-drying for $1 \mathrm{~h}$, the plates were stored at $-20^{\circ} \mathrm{C}$ until use.

\section{Immunostainings of pig serum and colostrum against PEDV-infected Vero cells}

To characterize and determine the PEDV-specific antibody titers of the serum and colostrum samples used in this study, the immunostaining of PEDV-infected Vero cells (ICC and IFA) was used as the gold standard. To determine the immunostaining titers of each samples, the serum or the colostrum was serially diluted with PBS (Gibco) from 160-fold to 20,480-fold in a volume of $200 \mu \mathrm{L} /$ well. The samples were added to the plates of PEDV-infected Vero cells prepared previously, incubated for $1 \mathrm{~h}$ at room temperature with gentle shaking, and washed six times with PBS (Gibco). Next, $200 \mu \mathrm{L}$ of the goat-anti-swine IgG secondary antibody conjugated with horseradish peroxidase (HRP) (KPL, SeraCare, MA, USA) or conjugated with fluorescence (Jackson Laboratory, ME, USA) was diluted 200-fold and added to the wells and incubated for $1 \mathrm{~h}$. After washing six times with PBS (Gibco), the staining was visualized using the EnVision-DAB+ system (Dako, Santa Clara, CA, USA) or by observing the fluorescence under a microscope. To standardize the coloration procedure, each plate included the same positive serum diluted 5120-fold as the positive control and the color development was stopped once the positive control colorized. The color development was evaluated using an inverted light/fluorescence microscope. To avoid any possible non-specific signals of the immunostaining, a signal 
was only considered positive when appearing on syncytial Vero cells, which show the CPE. If the signals appeared on the morphologically normal Vero cells but not on the CPE cells, the result was considered negative.

\section{Protein expression and characterization of different lengths of S protein of G2b PEDV-PT}

The full-length and truncated S proteins of G2b PEDV-PT, including protein sequences containing aa $1-435\left(\mathrm{~S}^{1-435}\right), 1-$ $485\left(\mathrm{~S}^{1-485}\right), 1-501\left(\mathrm{~S}^{1-501}\right), 1-509\left(\mathrm{~S}^{1-509}\right), 1-575\left(\mathrm{~S}^{1-575}\right)$, and 1-639 $\left(\mathrm{S}^{1-639}\right)$, were constructed and expressed in HEK-293 cells as previously described [17, 32]. These PEDV S-expressing HEK-293 cells were selected using geneticin (Gibco) containing DMEM (Gibco) after two weeks and became stable protein expressing cell lines. To compare the protein yield of the full-length and truncated $\mathrm{S}$ proteins of G2b PEDV-PT expressing HEK cells, each protein was purified from $40 \mathrm{~mL}$ FreeStyle 293 expression medium (Gibco) and eluted with $1 \mathrm{~mL}$ buffer as previously described [17, 32]. The concentration of each $\mathrm{S}$ protein was measured using the Pierce ${ }^{\mathrm{Tx}}$ BCA Protein Assay Kit (Thermo Fisher Scientific) according to the manufacturer's protocol. To determine the purity and quality of the truncated $\mathrm{S}$ protein used for ELISA, the truncated $S$ protein was first denatured in NuPAGE ${ }^{\bullet}$ LDS sample buffer (Thermo Fisher Scientific) containing the NuPAGE ${ }^{\ominus}$ reducing agent (Thermo Fisher Scientific), and boiled at $95^{\circ} \mathrm{C}$ for $5 \mathrm{~min}$. The denatured protein was separated by $10 \%$ SDS-PAGE and detected by the Coomassie blue (Bio-rad) protein dye.

\section{Commercial PEDV enzyme-linked immunosorbent assays (ELISAs)}

A commercial $\mathrm{N}$ protein-based PEDV ELISA kit, ID Screen $^{\circ}$ PEDV Indirect (IDVet, Montpellier, France), was used in this study according to the manufacturer's instructions. Briefly, $10 \mu \mathrm{L}$ of serum was added to each well containing $90 \mu \mathrm{L}$ of dilution buffer 11 (IDVet), resulting in a ten-fold dilution. After incubation at $25^{\circ} \mathrm{C}$ for $45 \mathrm{~min}$, the wells were washed three times with Wash solution (IDVet), then $100 \mu \mathrm{L}$ of $1 \times$ conjugate diluted in dilution buffer 3 (IDVet) was added. This mixture was incubated for another $30 \mathrm{~min}$. After washing three times, $100 \mu \mathrm{L}$ of substrate (IDVet) was added to the wells and allowed to react for coloration for $15 \mathrm{~min}$ before the stop solution (IDVet) was used to stop the coloration reaction. The plates were read at $405 \mathrm{~nm}$ using the EMax Plus Microplate Reader (Molecular Devices, Crawley, UK). As per the manufacturer's instructions, the $\mathrm{S} / \mathrm{P}$ ratio was interpreted as negative when the $S / P$ ratio $<0.6$ and positive when the $S / P$ ratio $\geq 0.6$.

\section{Development of full-length S-based and $\mathrm{S}^{1-501}$-based ELISAs} The recombinant $\mathrm{S}$ proteins were diluted to $2 \mu \mathrm{g} / \mathrm{mL}$ with coating buffer (KPL, SeraCare, MA, USA) and were coated on a Nunc maxi-soap plate (Thermo Fisher Scientific) at $4{ }^{\circ} \mathrm{C}$ for $16 \mathrm{~h}$. After washing six times with washing buffer (KPL, SeraCare), each well was blocked with $300 \mu \mathrm{L}$ blocking buffer (KPL, SeraCare) at room temperature for $1 \mathrm{~h}$. The serum samples were diluted 40-fold in blocking buffer and then $100 \mu \mathrm{L}$ was added per well to washed plates and incubated for $1 \mathrm{~h}$ at room temperature. After washing six times, as previously described, HRP-conjugated goat-antiswine IgG antibody (KPL, SeraCare) was added to the wells at 1:1000 dilution and the plates were then incubated for 1 $\mathrm{h}$ at room temperature. The coloration procedure was initiated by applying $50 \mu \mathrm{L} /$ well of $\mathrm{ABTS}^{\circ}$ Peroxidase Substrate System (KPL, SeraCare) onto the washed plates, and the coloration step was stopped by adding $50 \mu \mathrm{L} /$ well stopping solution (KPL, SeraCare). The signals were read at $405 \mathrm{~nm}$ using the EMax Plus Microplate Reader (Molecular Devices). In the ELISA assays, a double-positive sample for both immunostaining against PEDV-infected Vero cells and commercial PEDV ELISA was chosen as the interexperimental positive control; similarly, a double-negative serum was chosen as the negative control in this study.

\section{Determination of cut-off value, sensitivity, and specificity of ELISA}

To determine the cut-off value of the different truncated S-based ELISAs, 213 negative serum samples (from the $\mathrm{C}-\mathrm{N}$ and SPF-N groups) and 90 positive serum samples (from the C-I, SPF-I, and Sow-F groups), which were used for the immunostaining against PEDV-infected Vero cells, were analyzed in duplicate by these ELISAs and data are expressed as the $\mathrm{S} / \mathrm{P}$ ratio. The optimal cut-off value for each ELISA was analyzed and determined by ROC analysis and SPSS Statistics to obtain the best combination of sensitivity and specificity.

\section{Statistical measurement of testing agreement}

To measure the inter-rater agreements of different ELISAs, the Cohen's kappa coefficient values between the results of immunostaining, commercial PEDV-N ELISA, full-length S-based ELISA, and $S^{1-501}$-based ELISA were calculated and compared. The strength of agreements was considered as described: kappa value $\leqq 0$ : poor; $0.01-0.20$ : slight; $0.21-0.40$ : fair; $0.41-0.60$ : moderate; $0.61-0.80$ : substantial; 0.81-1: almost perfect. The repeatability of the full-length S-based ELISA and $S^{1-501}$-based ELISA was evaluated by analyzing all of the serum samples in duplicate and obtaining the mean S/P ratio of each sample.

\section{Colostrum IgA detection using full-length S-based and $S^{1-501}$-based ELISAs}

To evaluate whether the S-based ELISAs developed in the present study could detect PEDV specific mucosal IgA, colostrum from PEDV seropositive and negative pigs was used. Five colostrum samples from the PEDV 
sero-negative SPF sows and 23 colostrum samples from the PEDV sero-positive conventional sows pre-exposed with G2b PEDV by natural infection or feedback were included in this study. The colostrum was centrifuged at $3000 \mathrm{rpm}$ for $30 \mathrm{~min}$ to obtain the milk serum. The ELISA procedure as described above was followed with only two modifications: The milk serum was diluted $80-$ fold and used as the primary antibody and the anti-pig IgA HRP-conjugated antibody (Sigma) was diluted 10, 000-fold and used as the secondary antibody. The readout of the ELISA was calculated as the S/P ratio.

\section{Construction, expression, and purification of G1b PEDV S protein}

To determine the cross-reactivity of our G2b PEDV-PT S-based ELISA with a G1b PEDV, it was first necessary to produce a G1b PEDV S protein in order to obtain the porcine G1b PEDV hyperimmune serum. The G1b PEDV used in this study was Taiwan historic PEDV strain (GenBank: HC070225). The gene encoding the S protein was synthesized, codon-optimized, and cloned into a $\mathrm{pcDNA}^{\mathrm{Tm}} 3.1 / \mathrm{V} 5-\mathrm{His} \mathrm{TOPO}^{\circ}$ vector (Invitrogen), as previously described $[17,32]$. The characterization of the S protein of the Taiwan historic PEDV-HC070225 strain was verified using western blotting as previously described [17, 32].

\section{Evaluation of cross-reactivity of G2b PEDV-PT S-based ELISAs with G1b PEDV}

A post-weaning, conventional PEDV naïve $(\mathrm{C}-\mathrm{N})$ pig was purchased and injected intramuscularly with $50 \mu \mathrm{g}$ of Taiwan historic PEDV strain (GenBank: HC070225) S protein with Freund's adjuvant (Sigma) three times at 2week intervals. The serum sample was obtained two weeks after the third injection. The serum sample was serially diluted from 160 -fold to 20,480-fold and ICC was carried out against G2b-PEDV-PT infected Vero cells to determine the titer of the immunostaining. Finally, the serum was used in both the commercial $\mathrm{N}$ protein-based ID Screen ${ }^{\circ}$ PEDV Indirect (IDVet) ELISA and our G2b PEDV-PT S-based ELISAs, following the same procedure described above, to evaluate the crossreactivity of the ELISAs.

\section{Supplementary information}

Supplementary information accompanies this paper at https://doi.org/10. 1186/s12917-019-2171-7.

Additional file 1: Figure $\mathbf{S} 1$. The evaluation of purity of $S^{1-501}$ protein on the sodium dodecyl sulfate (SDS)-polyacrylamide gel electrophoresis (PAGE). The purified recombinant $\mathrm{S}^{1-501}$ was separated by the SDS-PAGE and stained with the Coomassie blue protein dye. The molecular weight of the recombinant $\mathrm{S}^{1-501}$ protein was approximately $75 \mathrm{kDa}$, respectively. The protein ladder $(\mathrm{M})$ is shown in kilodalton $(\mathrm{kDa})$. The star icon indicated the $\mathrm{S}^{1-501}$ protein on the SDS-PAGE.

\section{Abbreviations}

ATCC: American Type Culture Collection; C-I: Experimental PEDV inoculated conventional pigs; C-N: Conventional PEDV naïve pigs; COE epitope: CO-26 K equivalent epitope; CPE: Cytopathic effect; E: Envelop; ELISA: Indirect enzyme-linked immunosorbent assay; G2: Genotype 2; HEK 293: Human embryonic cell 293; HRP: Horseradish peroxidase; IACUC: Institutional Animal Care and Use Committee; ICC: Immunocytochemical; M: Membrane; N: Nucleocapsid; NTU: National Taiwan University; PED: Porcine epidemic diarrhea; PEDV: Porcine epidemic diarrhea virus; PEDV-PT: G2b PEDV Pintung 52 strain; PEDV-PT-P6: G2b PEDV Pintung 52 strain passage 6; PI medium: Post-inoculation medium; S: Spike; S/P ratio: Sample to positive ratio; $S^{1-435}$ : a.a.1-435 of S protein; $S^{1-485}$ : a.a.1-485 of $S$ protein; $S^{1-501}$ : a.a.1501 of $S$ protein; $S^{1-501}$ : Amino acid 1-501 of G2b PEDV-PT S protein; $S^{1-}$

509: a.a.1-509 of $S$ protein; $S^{1-575}$ : a.a.1-575 of $S$ protein; $S^{1-639}$ : a.a.1-639 of $S$ protein; SD: Standard deviation; Sow-F: PEDV-feedback sows; SPF-

I: Experimental PEDV inoculated SPF pigs; SPF-N: Specific pathogen free PEDV naïve pigs

\section{Acknowledgements}

We appreciate Dr. Ivan-Chen Cheng and Dr. Chi-Min Chen for providing valuable materials. We also thank Zhi-Kai Yang for the assistant on the statistical analysis.

\section{Authors' contributions}

CYC: conducted the experimental design, experiment performance, analysis, interpretation of data, and manuscript writing. JYP: experiment performance, analysis, interpretation of data. YHC: analysis and perform the experiment. YCC: perform the experiment and interpretation of data. YTW: designed and constructed the protein. PST: manuscript writing and interpretation of data; HYC: experimental design and interpretation of data; CRJ: interpretation of data and analysis; HWC: conducted the conception and design, analysis/ interpretation of data, manuscript amendment. All authors had read and approved this manuscript.

\section{Funding}

This work was supported by the Ministry of Science and Technology, Taiwan, R.O.C. for grants MOST106-2311-B-002-028-MY3, MOST107-2321-B-033-002-, 108 L7842 and 107 L7842 from National Taiwan University, Taiwan, ROC. The funding body had no role in the design of the study and collection, analysis, and interpretation of data and in writing the manuscript.

\section{Availability of data and materials}

The datasets used and/or analyzed during the current study are available from the corresponding author on reasonable request.

\section{Ethics approval and consent to participate}

The procedures involving animals were approved and permitted by the Institutional Animal Care and Use Committee (IACUC) of National Taiwan University (NTU; Taiwan, Republic of China) and carried out under the regulations of the IACUC protocol at NTU with the approval number of 106EL-00054. All samples in this study were collected and used with the written agreement of the farm owners. The written informed consent of each submission has been obtained from all owners together with the sample submission form.

Consent for publication

Not applicable.

Competing interests

The authors declare that they have no competing interests.

\section{Author details}

${ }^{1}$ Graduate Institute of Molecular and Comparative Pathobiology, School of Veterinary Medicine, National Taiwan University, No. 1, Section 4, Roosevelt Rd., Taipei 10617, Taiwan. ${ }^{2}$ School of Veterinary Medicine, National Taiwan University, Taipei 10617, Taiwan. ${ }^{3}$ Graduate Institute of Veterinary Pathobiology, College of Veterinary Medicine, National Chung Hsing University, Taichung 402, Taiwan. 
Received: 1 March 2019 Accepted: 8 November 2019

\section{10.0100}

\section{References}

1. Jung K, Saif LJ. Porcine epidemic diarrhea virus infection: etiology, epidemiology, pathogenesis and immunoprophylaxis. Vet J. 2015;204(2): 134-43.

2. Jung $K$, Annamalai T, Lu Z, Saif $\sqcup$. Comparative pathogenesis of US porcine epidemic diarrhea virus (PEDV) strain PC21A in conventional 9-day-old nursing piglets vs. 26-day-old weaned pigs. Vet Microbiol. 2015;178(1):31-40.

3. Wang Q, Vlasova AN, Kenney SP, Saif L. Emerging and re-emerging coronaviruses in pigs. Curr Opin Virol. 2019;34:39-49.

4. Song D, Moon H, Kang B. Porcine epidemic diarrhea: a review of current epidemiology and available vaccines. Clin Exp Vaccine Res. 2015;4(2):166-76.

5. Lai MM, Cavanagh D. The molecular biology of coronaviruses. Adv Virus Res. 1997:48:1-100

6. Saif LJ. Coronavirus immunogens. Vet Microbiol. 1993;37(3):285-97.

7. Utiger A, Tobler K, Bridgen A, Ackermann M. Identification of the membrane protein of porcine epidemic diarrhea virus. Virus Genes. 1995;10(2):137-48

8. Li W, van Kuppeveld FJM, He Q, Rottier PJM, Bosch B-J. Cellular entry of the porcine epidemic diarrhea virus. Virus Res. 2016;226:117-27.

9. Li C, Li W, Lucio de Esesarte E, Guo H, van den Elzen P, Aarts E, van den Born E, Rottier PJM, Bosch B-J. Cell attachment domains of the porcine epidemic diarrhea virus spike protein are key targets of neutralizing antibodies. J Virol. 2017;91(12):e00273-17.

10. Song Q, Stone S, Drebes D, Greiner LL, Dvorak CMT, Murtaugh MP. Characterization of anti-porcine epidemic diarrhea virus neutralizing activity in mammary secretions. Virus Res. 2016;226:85-92.

11. de Haan CAM, Haijema BJ, Schellen P, Schreur PW, te Lintelo E, Vennema H, Rottier PJM. Cleavage of group 1 coronavirus spike proteins: how Furin cleavage is traded off against Heparan sulfate binding upon cell culture adaptation. J Virol. 2008;82(12):6078-83.

12. Walls AC, Tortorici MA, Bosch B-J, Frenz B, Rottier PJM, DiMaio F, Rey FA, Veesler D. Cryo-electron microscopy structure of a coronavirus spike glycoprotein trimer. Nature. 2016;531:114.

13. Chang S-H, Bae J-L, Kang T-J, Kim J, Chung G-H, Lim C-W, Laude H, Yang M$S$, Jang Y-S. Identification of the epitope region capable of inducing neutralizing antibodies against the porcine epidemic diarrhea virus. Mol Cells. 2002;14(2):295-9.

14. Sun DB, Feng L, Shi HY, Chen JF, Liu SW, Chen HY, Wang YF. Spike protein region (aa 636789) of porcine epidemic diarrhea virus is essential for induction of neutralizing antibodies. Acta Virol. 2007;51(3):149-56.

15. Cruz DJM, Kim C-J, Shin H-J. The GPRLQPY motif located at the carboxyterminal of the spike protein induces antibodies that neutralize porcine epidemic diarrhea virus. Virus Res. 2008;132(1):192-6.

16. Okda FA, Lawson S, Singrey A, Nelson J, Hain KS, Joshi LR, ChristopherHennings J, Nelson EA, Diel DG. The S2 glycoprotein subunit of porcine epidemic diarrhea virus contains immunodominant neutralizing epitopes. Virology. 2017:509:185-94.

17. Chang C-Y, Cheng I-C, Chang Y-C, Tsai P-S, Lai S-Y, Huang Y-L, Jeng C-R, Pang VF, Chang H-W. Identification of neutralizing monoclonal antibodies targeting novel conformational epitopes of the porcine epidemic Diarrhoea virus spike protein. Sci Rep. 2019;9(1):2529.

18. Pensaert MB, de Bouck P. A new coronavirus-like particle associated with diarrhea in swine. Arch Virol. 1978;58(3):243-7.

19. Shibata I, Tsuda T, Mori M, Ono M, Sueyoshi M, Uruno K. Isolation of porcine epidemic diarrhea virus in porcine cell cultures and experimental infection of pigs of different ages. Vet Microbiol. 2000;72(3-4):173-82.

20. Sun R-Q, Cai R-J, Chen Y-Q, Liang P-S, Chen D-K, Song C-X. Outbreak of porcine epidemic diarrhea in suckling piglets, China. Emerg Infect Dis. 2012; 18(1):161-3.

21. Niederwerder MC, Hesse RA. Swine enteric coronavirus disease: a review of 4 years with porcine epidemic diarrhoea virus and porcine deltacoronavirus in the United States and Canada. Transbound Emerg Dis. 2018;65(3):660-75.

22. Okda F, Liu X, Singrey A, Clement T, Nelson J, Christopher-Hennings J, Nelson EA, Lawson S. Development of an indirect ELISA, blocking ELISA, fluorescent microsphere immunoassay and fluorescent focus neutralization assay for serologic evaluation of exposure to north American strains of porcine epidemic diarrhea virus. BMC Vet Res. 2015;11:180.
23. Ren X, Suo S, Jang YS. Development of a porcine epidemic diarrhea virus M protein-based ELISA for virus detection. Biotechnol Lett. 2011; 33(2):215-20.

24. Hou XL, Yu LY, Liu J. Development and evaluation of enzyme-linked immunosorbent assay based on recombinant nucleocapsid protein for detection of porcine epidemic diarrhea (PEDV) antibodies. Vet Microbiol. 2007;123(1-3):86-92

25. Gimenez-Lirola LG, Zhang J, Carrillo-Avila JA, Chen Q, Magtoto R, Poonsuk K Baum DH, Piñeyro P, Zimmerman J. Reactivity of porcine epidemic diarrhea virus structural proteins to antibodies against porcine enteric coronaviruses: diagnostic implications. J Clin Microbiol. 2017;55(5):1426-36.

26. Gerber PF, Gong Q, Huang Y-W, Wang C, Holtkamp D, Opriessnig T. Detection of antibodies against porcine epidemic diarrhea virus in serum and colostrum by indirect ELISA. Vet J. 2014;202(1):33-6.

27. Knuchel M, Ackermann M, Muller HK, Kihm U. An ELISA for detection of antibodies against porcine epidemic diarrhoea virus (PEDV) based on the specific solubility of the viral surface glycoprotein. Vet Microbiol. 1992;32(2): 117-34.

28. Lin H, Zhou H, Gao L, Li B, He K, Fan H. Development and application of an indirect ELISA for the detection of antibodies to porcine epidemic diarrhea virus based on a recombinant spike protein. BMC Vet Res. 2018; $14(1): 243$.

29. Braakman I, Bulleid NJ. Protein folding and modification in the mammalian endoplasmic reticulum. Annu Rev Biochem. 2011;80:71-99.

30. Seiradake E, Zhao Y, Lu W, Aricescu AR, Jones EY. Production of Cell Surface and Secreted Glycoproteins in Mammalian Cells. In: Owens RJ, editor. Structural Proteomics: High-Throughput Methods. New York: Springer New York; 2015. p. 115-27.

31. Chang C-Y, Hsu W-T, Chao Y-C, Chang H-W. Display of porcine epidemic diarrhea virus spike protein on Baculovirus to improve immunogenicity and protective efficacy. Viruses. 2018;10(7):346.

32. Chang YC, Chang CY, Tsai PS, Chiou HY, Jeng CR, Pang VF, Chang HW. Efficacy of heat-labile enterotoxin B subunit-adjuvanted parenteral porcine epidemic diarrhea virus trimeric spike subunit vaccine in piglets. Appl Microbiol Biotechnol. 2018;102(17):7499-507.

33. Fan J-H, Zuo Y-Z, Shen X-Q, Gu W-Y, Di J-M. Development of an enzymelinked immunosorbent assay for the monitoring and surveillance of antibodies to porcine epidemic diarrhea virus based on a recombinant membrane protein. J Virol Methods. 2015;225:90-4.

34. Moremen KW, Tiemeyer M, Nairn AV. Vertebrate protein glycosylation: diversity, synthesis and function. Nat Rev Mol Cell Biol. 2012;13(7):448-62.

35. Belouzard S, Millet JK, Licitra BN, Whittaker GR. Mechanisms of coronavirus cell entry mediated by the viral spike protein. Viruses. 2012;4(6):1011-33.

36. Sissoeff $L$, Mousli M, England $P$, Tuffereau C. Stable trimerization of recombinant rabies virus glycoprotein ectodomain is required for interaction with the p75NTR receptor. J Gen Virol. 2005;86(Pt 9):2543-52.

37. Sanders RW, Derking R, Cupo A, Julien JP, Yasmeen A, de Val N, Kim HJ, Blattner C, de la Pena AT, Korzun J, et al. A next-generation cleaved, soluble HIV-1 Env trimer, BG505 SOSIP.664 gp140, expresses multiple epitopes for broadly neutralizing but not non-neutralizing antibodies. PLoS Pathog. 2013; 9(9):e1003618.

38. Oh J, Lee K-W, Choi H-W, Lee C. Immunogenicity and protective efficacy of recombinant S1 domain of the porcine epidemic diarrhea virus spike protein. Arch Virol. 2014;159(11):2977-87.

39. Paudel $\mathrm{S}$, Park JE, Jang H, Shin HJ. Comparison of serum neutralization and enzyme-linked immunosorbent assay on sera from porcine epidemic diarrhea virus vaccinated pigs. Vet Q. 2014;34(4):218-23.

40. Van Diep N, Sueyoshi M, Norimine J, Hirai T, Myint O, Teh APP, Izzati UZ, Fuke N, Yamaguchi R. Molecular characterization of US-like and Asian non-S INDEL strains of porcine epidemic diarrhea virus (PEDV) that circulated in Japan during 2013-2016 and PEDVs collected from recurrent outbreaks. BMC Vet Res. 2018;14:96.

41. Wen Z, Li J, Zhang Y, Zhou Q, Gong L, Xue C, Cao Y. Genetic epidemiology of porcine epidemic diarrhoea virus circulating in China in 2012-2017 based on spike gene. Transbound Emerg Dis. 2018;65(3):883-9.

42. Guo J, Fang L, Ye X, Chen J, Xu S, Zhu X, Miao Y, Wang D, Xiao S. Evolutionary and genotypic analyses of global porcine epidemic diarrhea virus strains. Transbound Emerg Dis. 2019;66(1):111-8.

43. Lin C-M, Gao X, Oka T, Vlasova AN, Esseili MA, Wang Q, Saif L. Antigenic relationships among porcine epidemic diarrhea virus and transmissible gastroenteritis virus strains. J Virol. 2015;89(6):3332-42. 
44. Chang YC, Kao CF, Chang CY, Jeng CR, Tsai PS, Pang VF, Chiou HY, Peng JY, Cheng IC, Chang HW. Evaluation and Comparison of the Pathogenicity and Host Immune Responses Induced by a G2b Taiwan Porcine Epidemic Diarrhea Virus (Strain Pintung 52) and Its Highly Cell-Culture Passaged Strain in Conventional 5-Week-Old Pigs. Viruses. 2017;9:5.

\section{Publisher's Note}

Springer Nature remains neutral with regard to jurisdictional claims in published maps and institutional affiliations.

Ready to submit your research? Choose BMC and benefit from:

- fast, convenient online submission

- thorough peer review by experienced researchers in your field

- rapid publication on acceptance

- support for research data, including large and complex data types

- gold Open Access which fosters wider collaboration and increased citations

- maximum visibility for your research: over $100 \mathrm{M}$ website views per year

At $\mathrm{BMC}$, research is always in progress.

Learn more biomedcentral.com/submissions 